\title{
Edge Effect Analysis on orthogonal cutting the Plastic Metal Material-C10100 with Negative Rake Angle Tool
}

\author{
Yanchun Ding ${ }^{1}$, Guangfeng Shi $^{2 *}$ \\ ${ }^{1}$ College of Mechanical and Electric Engineering Changchun University of Science and Technology Changchun China \\ ${ }^{2}$ College of Mechanical and Electric Engineering Changchun University of Science and Technology Changchun China
}

\begin{abstract}
With the rapid development of the precision grinding and micro-cutting technology, scholars have become more and more interested in the forming mechanism and related characteristics of the rounded-edge tool and the negative rake angle tool. Based on DEFORM-2D forming software, this paper investigates the edge effect of the negative rake angle tool in micro-cutting condition. Through the simulation comparison analysis, it is clear that three deformation regions appear in front of the tool surface, namely the first shear-slip region, the second tool-material contact friction region and the third edge effect deformation region when the negative rake tool cuts the plastic metal material-C10100 with a large edge radius. And a triangle stagnant region appears in front of the tool surface due to the edge effect. By analysing the influence of the ratio of the edge radius to the cutting thickness on the mechanism of orthogonal cutting of negative rake tools, it is found that the minimum cutting thickness value is between $0.1 \sim 0.11$ in the cutting condition.
\end{abstract}

\section{INTRODUCTION}

With the rapid development of the single-abrasive grinding processing technology $[1,2]$ and ultra-precision machining technology [3-6], scholars have developed more and more interested in the project's research on the forming mechanism and related characteristics of the negative rake tool and rounded-edge in micro-cutting condition. The ratio of the edge radius to the cutting thickness changes the effective negative rake angle of the tool in a certain extent micro-cutting condition [7]. The ratio further changes the flow characteristics of the cutting material, chip generation morphology, machining surface quality and tool wear. Therefore, this paper investigates the edge effect of the negative rake angle tool and analyses the forming mechanism and related factors of the cutting material by using the DEFORM-2D forming software. The research content of this paper will provide some experimental guidance for the study of the internal forming mechanism and related characteristics of metal materials by considering the edge effect in orthogonal cutting the plastic materials with negative rake tool.

\section{DEFORM-2D ORTHOGONAL CUTTING MODEL OF THE ROUNDED-EDGE TOOL}

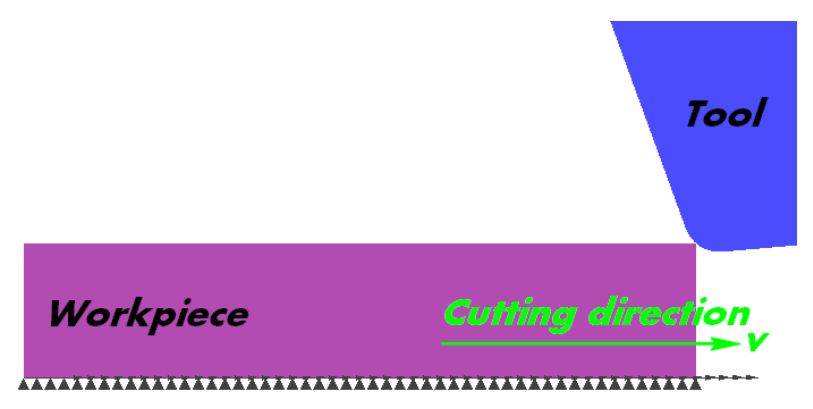

Figure 1. 2D-Orthogonal cutting FEM of the rounded-edge tool

The 2D-Orthogonal cutting FEM $[8,9]$ of the roundededge tool (negative rake angle tool with large cutting edge radius) is shown in Fig. 1. The basic parameters of the orthogonal cutting FEM are as follows: the cutting speed of the workpece is $1 \mathrm{~mm} / \mathrm{s}$ (the tool is fixed and the workpiece moves at uniform motion state), the cutting thickness is $0.2 \mathrm{~mm}$ (the cutting thickness is much smaller than that of the workpiece), and the friction coefficient of the tool-workpiece contact interface is 0.2 . The cutting tool is fixed and adopted diamond material, the negative rake angle of the cutting tool is $-20^{\circ}$, the relief angle of the tool is $5^{\circ}$, and the edge radius is the cutting variable, increasing from 0.4 to 1 (the value range will be used to investigate the edge effect). The tool is modeled as a rigid material with $\mathrm{E}=1140 \mathrm{GPa}$ and Poisson's ratio $=0.07$. 
C10100 is used as the workpiece, which are assumed to be isotropic with no residual stress. The material properties of $\mathrm{C} 10110$ is $\mathrm{E}=110 \mathrm{GPa}$ and Poisson's ratio $=0.33$. The Johnson-Cook $(\mathrm{J}-\mathrm{C})$ material model [10] is used to describe the true stress-strain relationship of the workpiece as the follow equation:

$$
\sigma=\left(A+B \varepsilon^{n}\right)\left(1+C \ln \frac{\dot{\varepsilon}}{\dot{\varepsilon}}\right)\left(1+\left(\frac{T-T_{r}}{T_{m}-T_{r}}\right) m\right)
$$

where $\sigma, \varepsilon, \varepsilon^{\cdot}, \varepsilon_{0}^{\cdot}$ are respectively the equivalent flow stress, equivalent plastic strain, equivalent plastic strain rate and reference strain rate. $\mathrm{T} m$ and $\mathrm{Tr}$ are the material melting temperature and reference ambient temperature,

respectively. The J-C constitutive plasticity model parameters of C10100 are shown as Table1.

TABLE 1. MATERIAL PARAMETER VALUES FOR THE J-C MODEL OF C10100

\begin{tabular}{cccccc}
\hline Material & $\mathrm{A} / \mathrm{Mpa}$ & $\mathrm{B} / \mathrm{Mpa}$ & $\mathrm{n}$ & $\mathrm{C}$ & $\mathrm{m}$ \\
\hline $\mathrm{C} 10100$ & 124.7 & 438.1 & 0.33 & 0.022 & 0.93 \\
\hline
\end{tabular}

\section{RESULTS AND DISCUSSION}

\subsection{Forming mechanism of the rounded edge tool}

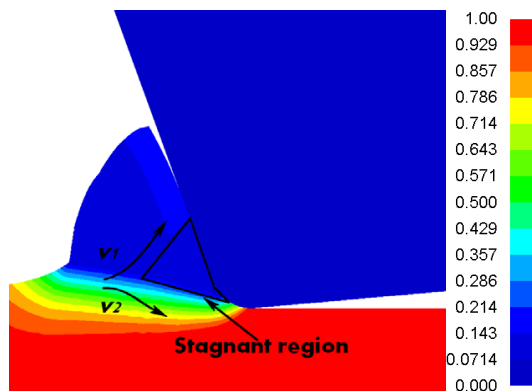

a.

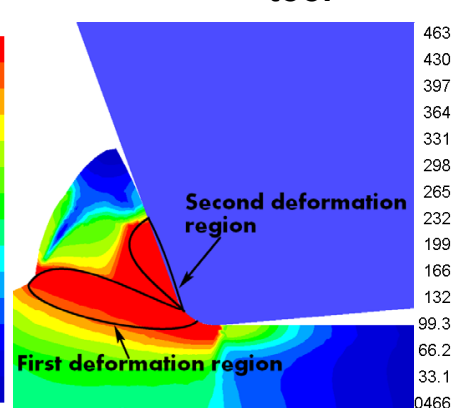

b.

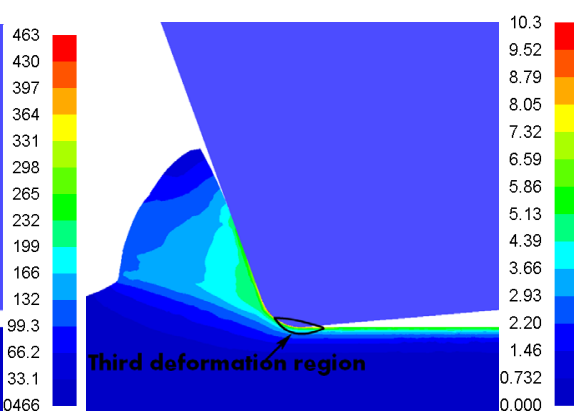

c.

Figure 2. Forming mechanism of the rounded-edge tool a. cloud diagram of cutting speed distribution b. cloud diagram of equivalent stress distribution c. cloud diagram of equivalent strain distribution

Three process variables of the rounded edge cutting C10100 material when the cutting speed is $1 \mathrm{~mm} / \mathrm{s}$, the ratio of cutting edge radius to cutting thickness is equal to 2, as shown in Fig. 2. The cloud diagrams of cutting speed distribution are shown in fig. 2a. It is clear that due to the rounded geometrical properties of cutter itself, the cutting tool edge transition was carried out on the material extrusion and adhesion effect. The internal friction of the material in front of the tool surface resulted in the formation of triangular stagnation area. This stagnant region is wrapped around the rounded-edge tool blade, which acts as the tool true surface. The simulation results are consistent with those obtained by the scholar Ohbuchi $\mathrm{Y}$ and Ding [6, 11]. And the stagnant region change the flow characteristics of the material, meanly some materials flow up along the stagnant region to form chips at the speed of $\boldsymbol{v} \boldsymbol{1}$, and some materials flow down along the stagnant region to form the processed surface at the speed of $\boldsymbol{v} 2$. The cloud diagrams of equivalent stress distribution of the roundededge tool are shown in Fig. 2b. It can be known that due to the stagnation region in front of the tool surface, the material in the first shear slip deformation area extends from the root of the chip to the bottom of the stagnant region instead of the tip of the tool. At the same time, the stress concentration at the cutting edge of the tool is obvious due to the drawing effect of the stagnant region. While the stress inside the detention area is small. This indicates that there is no large drawing action in the material of the stagnant region. The cloud diagrams of equivalent strain distribution of the rounded-edge tool are shown in Fig. 2c. It is clear that the equivalent strain value of the second and third deformation region is larger. This indicates that the compression and internal friction have the greatest effect on these two regions.

\subsection{Minimum uncut chip thickness of the rounded edge tool}

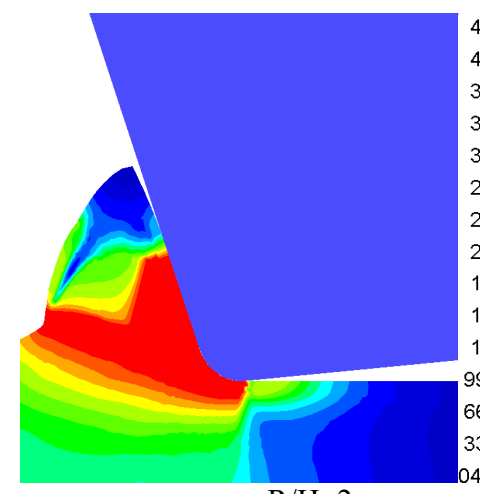

a. $\mathrm{R} / \mathrm{H}=2$
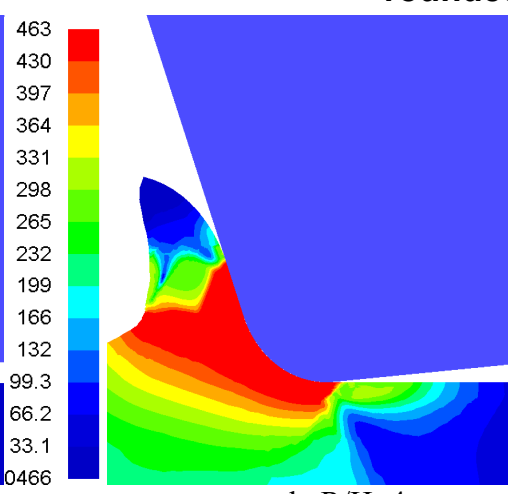

b. $\mathrm{R} / \mathrm{H}=4$
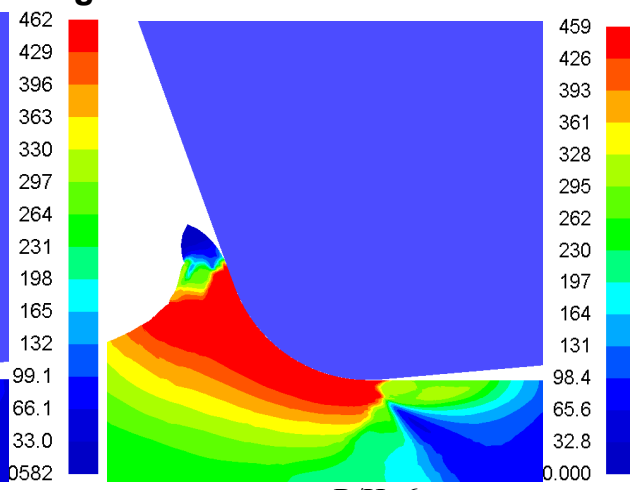

c. $\mathrm{R} / \mathrm{H}=6$ 


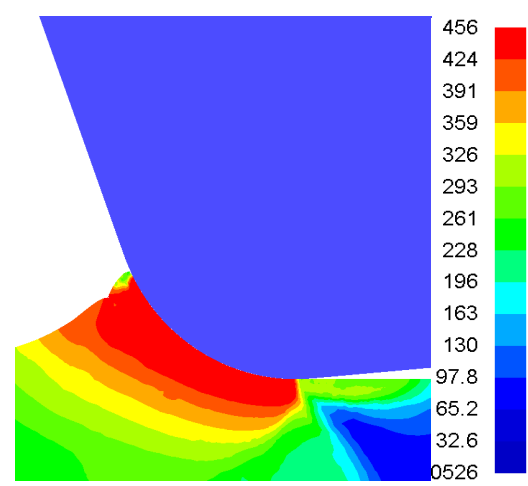

d. $\mathrm{R} / \mathrm{H}=8$

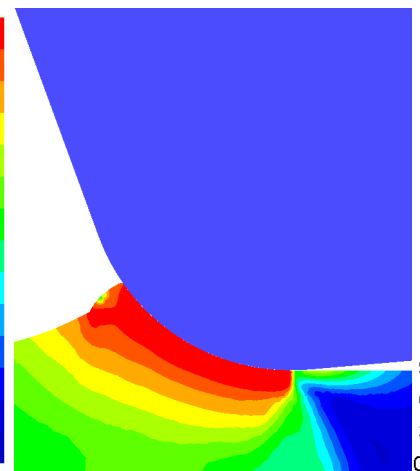

e. $\mathrm{R} / \mathrm{H}=9$

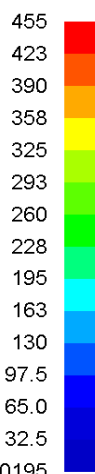

(195

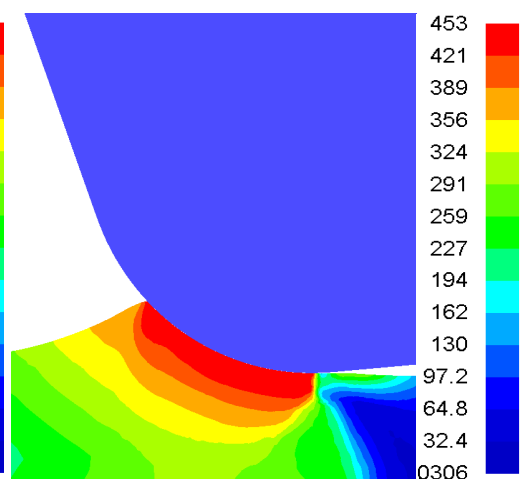

f. $\mathrm{R} / \mathrm{H}=10$

Figure 3. The stress distribution cloud graph of the rounded-edge tool

The stress distribution cloud graph of the rounded-edge tool cutting C10100 material when the cutting speed is $1 \mathrm{~mm} / \mathrm{s}$, as shown in Fig. 3 (a-f) (unit $/ \mathrm{MPa}$ ). When the ratio of cutting edge radius to cutting thickness increase from 2 to 9 , there is a significant stress concentration area appears and contactes the cutting tool tip with the free surface of the material, namely the first shear-slip deformation region. With the radius increasing, the chip shap change from slender to blunt, and the effect of the rounded-edge of the negative rake angle tool on the material changes from cutting to cutting and ploughing state. When ratio of cutting edge radius to cutting thickness is equal to 10 , the first deformation region wrap around the surface of rounded edge tool and donot contact the free surface disappears of the material. Meanwhile, no chips are generated in front of the tool surface, and the shear angle is approximately $0^{\circ}$. Meanly, the rounded-edge tool pure ploughing the C10100 material. In other words the minimum uncut chip thickness varied from $0.1 \mathrm{R}$ to $0.11 \mathrm{R}$ for $\mathrm{C} 10100$ in the cutting condition.

\section{CONCLUSION}

- $\quad$ Based on DEFORM-2D forming software, this paper investigates the edge effect of orthogonal cutting the Plastic metal material-C10100 with negative rake angle tool, the conclusions as follows:

- When the negative rake angle tool with large cutting edge radius is used in orthogonal cutting plastic metal material C10100, three deformation zones appears in front of the tool surface, namely, the first shear-slip region, the second deformation region- tool-material contact friction region, and the third deformation region, which is caused by the cutting edge effect.

- Because of the special geometric characteristics of the rounded-edge tool, the material in front of the tool surface forms a triangular-like stagnant region due to the extrusion and adhesion friction effect of the transition of the rounded-edge cutting tool.

- By analyzing the ratio of the cutting edge radius to cutting thickness, it is found that the first shear-slip deformation region gradually decreases and the ability to form chips before the cutting edge weakens when the ratio increase from 2 to 9 . The first shear-slip deformation region disappears, and the stress concentration area wraps the surface of the rounded-edge tool, and no chip is generated when the ratio is equal to 10 . In other words, the minimum cutting thickness value of this processing condition is between 0.1 and 0.11 .

- The above research work provides certain experimental guidance for the research of cutting edge effect on the molding mechanism and related characteristics of materials when the negative rake angle tool is used to orthogonal cut the plastic metal material.

\section{ACKNOWLEDGMENT}

The authors would like to acknowledge the Natural Science Foundation of China (NSFC) (Grant No. 51405031, No. 51575057 and No. 51075042) and the Science and Technology Project of Jilin Province (No. 20180414068GH, 20190302123GX).

\section{REFERENCES}

1. Chamani H R, Ayatollahi M R. The effect of berkovich tip orientations on friction coefficient in nanoscratch testing of metals[J]. Tribology International, 2016, 103:25-36.

2. Ding YC, Shi GF, Shi GQ (2018) Analysis of the stagnant characteristics of the material in the mechanical ruling process. Journal of Mechanical Engineering

3. Malekian M, Mostofa MG, Park SS, Jun MBG. Modeling of minimum uncut chip thickness in micro machining of aluminum[J]. Journal of Materials Processing Technology, 2012, 212(3):553-559

4. Sabri, Ozturk, Erhan, et al. Position of the separation point in machining with a rounded-edge tool[J]. Proceedings of the Institution of Mechanical Engineers, Part B: Journal of Engineering Manufacture, 2013.

5. Uysal A, Altan E. A New Slip-Line Field Modeling of Orthogonal Machining with a Rounded-Edge Worn Cutting Tool[J]. Machining Science and Technology, 2014, 18(3):386-423.

6. Mathias, Agmell, Daniel, et al. The Influence the Uncut Chip Thickness has on the Stagnation Point in Orthogonal Cutting[J]. Procedia CIRP, 2017. 
7. Ohbuchi Y, Obikawa T. Finite Element Modeling of Chip Formation in the Domain of Negative Rake Angle Cutting $[\mathrm{J}]$. Journal of Engineering Materials and Technology, 2003, 125(3):324. doi:10.1115/1.1590999

8. Duan CZ, Zhang LC. A reliable method for predicting serrated chip formation in high-speed cutting: analysis and experimental verification[J]. Int J Adv Manuf Technol, 2013, 64(9-12):1587-1597

9. Wan L, Wang DZ, Gao Y (2016) The investigation of mechanism of serrated chip formation under different cutting speeds. Int J Adv Manuf Technol 82(5-8):951-959

10. Johnson GR, Cook WH. Fracture characteristics of three metals subjected to various strains, strain rates, temperatures and pressures[J]. Engineering Fracture Mechanics, 1985, 21(1):31-48

11. Ding YC, Shi GF, Zhang H, Shi GQ, Han DD (2019) Analysis of critical negative rake angle and friction characteristics in orthogonal cutting of AL1060 and T2. Science Progress published online doi: $10.1177 / 0036850419878065$ 